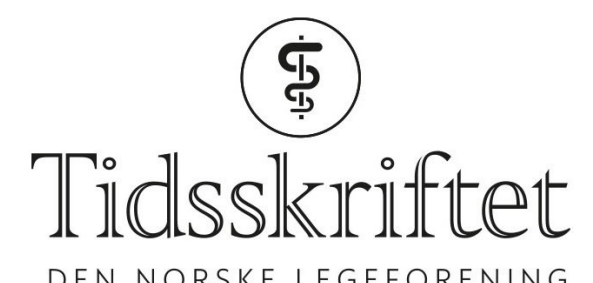

DEN NORSKE LEGEFORENING

\title{
Tourettes syndrom hos barn i Norge
}

ORIGINALARTIKKEL

\section{PÅL SURÉN}

E-post: pal.suren@fhi.no

Folkehelseinstituttet

Han har bidratt med datainnsamling og dataanalyse, utforming/design, tolking av data, litteratursøk og utarbeiding, revisjon og godkjenning av manus.

Pål Surén er lege og spesialist i barnesykdommer, har en ph.d.-grad i epidemiologi og er forsker.

Forfatteren har fylt ut ICMJE-skjemaet og oppgir ingen interessekonflikter.

\section{INGER JOHANNE BAKKEN}

Senter for fruktbarhet og helse

Folkehelseinstituttet

og

Helsedirektoratet

Hun har bidratt med datainnsamling og dataanalyse, utforming/design, tolking av data, litteratursøk og utarbeiding, revisjon og godkjenning av manus.

Inger Johanne Bakken er dr.ing. i biofysikk og medisinsk teknologi, seniorforsker og seniorrådgiver. Forfatteren har fylt ut ICMJE-skjemaet og oppgir ingen interessekonflikter.

\section{SVETLANA SKURTVEIT}

Folkehelseinstituttet

og

Universitetet i Oslo

Hun har bidratt med datainnsamling og dataanalyse, utforming/design, tolking av data, litteratursøk og utarbeiding, revisjon og godkjenning av manus.

Svetlana Skurtveit har doktorgrad i uorganisk kjemi og i biofysikalsk kjemi, er seniorforsker og professor II.

Forfatteren har fylt ut ICMJE-skjemaet og oppgir ingen interessekonflikter.

\section{MARTE HANDAL}

Folkehelseinstituttet

Hun har bidratt med datainnsamling og dataanalyse, utforming/design, tolking av data, litteratursøk og utarbeiding, revisjon og godkjenning av manus.

Marte Handal er ph.d., spesialist i klinisk farmakologi, overlege og seniorforsker.

Forfatteren har fylt ut ICMJE-skjemaet og oppgir ingen interessekonflikter.

\section{TED REICHBORN-KJENNERUD}

Folkehelseinstituttet

og

Universitetet i Oslo

Han har bidratt med utforming/design, tolking av data, litteratursøk og utarbeiding, revisjon og godkjenning av manus.

Ted Reichborn-Kjennerud er lege og spesialist i psykiatri, dr.med., avdelingsdirektør ved

Folkehelseinstituttet og professor.

Forfatteren har fylt ut ICMJE-skjemaet og oppgir ingen interessekonflikter. 
Folkehelseinstituttet

og

Universitetet i Bergen

Hun har bidratt med utforming/design, tolking av data, litteraturs $\emptyset \mathrm{k}$ og utarbeiding, revisjon og godkjenning av manus.

Camilla Stoltenberg er dr.med. i epidemiologi, direktør og professor II.

Forfatteren har fylt ut ICMJE-skjemaet og oppgir ingen interessekonflikter.

\section{IRENE NØSTVIK}

Norsk Tourette Forening

Larvik

Han har bidratt med utforming/design, tolking av data, litteratursøk og utarbeiding, revisjon og godkjenning av manus.

Liv Irene Nøstvik er daglig leder i Norsk Tourette Forening.

Forfatteren har fylt ut ICMJE-skjemaet og oppgir ingen interessekonflikter.

\section{BERNHARD WEIDLE}

St. Olavs hospital

og

Regionalt kunnskapssenter for barn og unge

Psykisk helse og barnevern i Midt-Norge

NTNU

Han har bidratt med utforming/design, tolking av data, litteratursøk og utarbeiding, revisjon og godkjenning av manus.

Bernhard Weidle er ph.d., spesialist i barnesykdommer og i barne- og ungdomspsykiatri, overlege og førsteamanuensis.

Forfatteren har fylt ut ICMJE-skjemaet og oppgir ingen interessekonflikter.

\section{BAKGRUNN}

Tourettes syndrom debuterer i barnealder og kjennetegnes av kroniske motoriske og vokale tics. I andre land er gjennomsnittsprevalensen beregnet til o,77 \% hos barn i alderen 6-15 år. I Norge er diagnosebruk og behandling ikke kartlagt.

\section{MATERIALE OG METODE}

Vi brukte data fra Norsk pasientregister og Folkeregisteret til å beregne andeler barn født i årene 2002-10 som er blitt diagnostisert med Tourettes syndrom. Beregningene ble gjort for landet som helhet og fylkesvis. Medikamentell behandling ble kartlagt med data fra Reseptregisteret.

\section{RESULTATER}

Ved 12 års alder hadde 0,43 \% fått diagnosen Tourettes syndrom, fordelt på o,71 \% hos gutter og 0,15\% hos jenter. De totale andelene varierte fra 0,15\% til 1,23\% mellom fylkene. For landet som helhet har andelene med diagnoser vært stabile fra 2008 til 2016. Tillegg av psykiatriske og nevrologiske tilstander var utbredt, og vanligst var hyperkinetisk forstyrrelse (50 \%) og autismespekterforstyrrelser (11\%). Antipsykotika, sannsynligvis til behandling av tics, ble gitt til $16 \%$ i året etter at diagnosen var stilt.

\section{FORTOLKNING}

Andelene barn som får diagnostisert Tourettes syndrom i Norge ligger under gjennomsnittsprevalensen i befolkningsstudier internasjonalt. Diagnosebruken varierer betydelig mellom fylkene.

Tourettes syndrom er en nevrologisk tilstand som debuterer i barnealder og kjennetegnes av motoriske og vokale tics (1). Tics er ufrivillige, raske, gjentatte, urytmiske motoriske 
bevegelser eller plutselige, utilsiktede vokale lyder. Tics forekommer ofte hos barn og er som regel forbigående. Diagnosen Tourettes syndrom brukes når minst to motoriske tics og ett eller flere vokale tics har vært til stede, men ikke nødvendigvis samtidig, i mer enn ett år. Ved Tourettes syndrom debuterer tics vanligvis ved 5-6 års alder og er mest intense i 10-12årsalderen (1). De fleste befolkningsbaserte studier av Tourettes syndrom er små, og anslagene av forekomst varierer betydelig (2). I en metaanalyse av prevalensstudier fant man en gjennomsnittsprevalens på o,77\% (2). Studiene var hovedsakelig utført i Europa og Nord-Amerika og omfattet barn i alderen 6-15 år. Prevalensen var høyere hos gutter enn hos jenter, med en gjennomsnittlig gutt-jente-ratio på 4,2 (2).

Studier basert på helseregisterdata har gitt lavere prevalens av Tourettes syndrom enn studier basert på representative utvalg av befolkningen. I Danmark får o,4-0,5\% av alle barn diagnosen før de fyller 15 år, mens tilsvarende andeler er 0,1-0,2 \% i Finland og under 0,1\% i Sverige (3). I Norge har bruken av diagnosen aldri blitt unders $\varnothing \mathrm{kt}$.

Genetisk disposisjon er den viktigste kjente risikofaktoren for Tourettes syndrom (4). I tvilling- og familiestudier er arvbarheten beregnet til $77 \%$. Patogenesen er ikke klarlagt, men MR-studier tyder på at personer med Tourettes syndrom har funksjonsforstyrrelser i nervebaner mellom hjernebarken og basalgangliene (1). Flertallet av de som har Tourettes syndrom, har også andre nevrologiske eller psykiatriske tilstander (1). I barne- og ungdomsalder er hyperkinetisk forstyrrelse (ADHD) og tvangslidelse de vanligste komorbide lidelsene $(1,4)$. Atferdsproblemer og sinne er vanlig, og emosjonelle problemer forekommer ofte i ungdomsårene. Over en tredjedel antas å ha vokst av seg Tourettes syndrom når de blir voksne, mens de andre tilstandene ofte vedvarer (1).

Den best dokumenterte ikke-medikamentelle behandlingsformen er ticskontrollerende trening (5), som også er førstevalget som behandling. Dette er kognitiv atferdsterapi hvor man lærer å motstå trangen til å utføre tics. I tillegg omfatter terapien avslapningsteknikker og psykososiale støttetiltak. Hvis tics forårsaker smerte, sosiale og emosjonelle problemer eller gjør det vanskelig å fungere normalt på skolen og i hverdagen, kan medikamentell behandling prøves (6). Studiene på medikamentell behandling er imidlertid små, og bare et fåtall har vært utført med randomisering, dobbeltblinding og placebokontroll.

I de europeiske retningslinjene for behandling av Tourettes syndrom er risperidon, et atypisk antipsykotikum, anbefalt som førstevalg (7). Aripiprazol, et nyere atypisk antipsykotikum, omtales også positivt i disse retningslinjene. Klonidin, et antiadrenergikum, anbefales til kombinert behandling av Tourettes syndrom og ADHD. I Norge er det laget en regional retningslinje for Helse $S \emptyset \mathrm{r}-\emptyset_{\mathrm{st}}$, og anbefalingene der er i tråd med de europeiske retningslinjene (6). Aripiprazol og klonidin kan dekkes ved søknad om individuell refusjon, men dette gjelder kun for barn og ikke for voksne. Risperidon refunderes ikke.

I denne studien har vi brukt data fra Norsk pasientregister for å beregne andeler barn og unge som får diagnostisert Tourettes syndrom, for landet som helhet og fylkesvis. Vi har også kartlagt hvilke andre psykiatriske og nevrologiske diagnoser som stilles hos disse barna og ungdommene. Ved å kombinere data fra Norsk pasientregister og Reseptregisteret har vi studert bruk av psykofarmaka og andre medikamenter som virker på sentralnervesystemet. Analysene er initiert av Autisme- og touretteutvalget, et regjeringsoppnevnt utvalg som ble nedsatt i 2018 for å utrede tjenestetilbudet til personer med autismespekterforstyrrelser og Tourettes syndrom.

\section{Materiale og metode}

Norsk pasientregister har personidentifiserbare data fra 2008 og fremover. I denne studien brukte vi data om barn og ungdom som har vært i kontakt med psykisk helsevern for barn og unge, somatiske sykehus og avtalespesialister fra og med 2008 til og med 2016. Tourettes syndrom ble definert som én eller flere registreringer av ICD-10-diagnosekode F95.2 Kombinerte vokale og multiple motoriske «tics», Tourettes syndrom. 
Tourettes syndrom diagnostiseres som regel fra seks års alder og oppover i Norge. Vi inkluderte alle barn født fra og med 2002 til og med 2010, det vil si alle som kan være registrert i Norsk pasientregister fra kalenderåret de fylte seks år. Deretter estimerte vi andelen som hadde fått diagnosen $i$ aldersgruppen 6-14 år ved hjelp av Kaplan-Meieranalyser, både for landet som helhet og fylkesvis. Blant de som hadde fått diagnosen, kartla vi også hvilke andre psykiatriske og nevrologiske diagnoser som var registrert i årene 2008-16.

Ved slutten av oppfølgingstiden var populasjonen i alderen 6-14 år, men vi valgte å avslutte Kaplan-Meier-kurvene ved 12 års alder fordi de fylkesvise estimatene ble usikre for 13- og 14åringer. De fylkesvise sammenligningene er derfor gjort for 12-åringer. For de fylkesvise estimatene beregnet vi konfidensintervaller for å sammenligne fylkene med landsgjennomsnittet. Fordi vi gjorde mange sammenligninger (19 fylker), brukte vi strenge konfidensintervaller (99,7\% basert på Bonferroni-korreksjon). Analysene ble gjort i Stata 15 (Stata Statistical Software, StataCorp. 2017).

Vi undersøkte også hvor mange barn og ungdommer i populasjonen som var registrert med diagnosekode F95.1 Kroniske motoriske eller vokale «tics». Denne koden skal brukes på de som har enten motoriske eller vokale tics i ett år eller lenger, men ikke både motoriske og vokale tics som ved Tourettes syndrom.

Vi ønsket i tillegg å studere eventuelle endringer i bruk av diagnosen Tourettes syndrom over tid. Derfor beregnet vi andeler barn registrert med diagnosen innen hvert kalenderår fra 2008 til 2016, fordelt på kjønn og aldersgrupper. Disse beregningene inkluderte alle som var i alderen 6-17 år i det aktuelle kalenderåret. Befolkningsdata ble hentet fra Folkeregisteret.

I analysene av medikamentbruk brukte vi en kobling mellom data fra Norsk pasientregister og data fra Reseptregisteret. Koblingen inneholdt data fra og med 2008 til og med 2015. Vi kartla medikamentbruk hos alle i alderen 6-17 år som var registrert med Tourettes syndrom for første gang i årene 2013 og 2014. Kartleggingen omfattet medikamenter som ble forskrevet de første 365 dagene etter at diagnosen var registrert for første gang. Vi begrenset kartleggingen til nyregistrerte diagnoser fordi vi ville unders $ø$ ke behandling som ble gitt i sammenlignbare perioder etter at diagnosen ble stilt.

Bruk av data fra Norsk pasientregister er godkjent av Datatilsynet (ref. 15/01648). Kobling av data fra Norsk pasientregister og Reseptregisteret for analyser av medikamentbruk er godkjent av Datatilsynet (ref. 10/oo447) og Regional etisk komité (ref. 2010/131).

\section{Resultater}

Det var totalt 556917 barn som var født i årene 2002-10 og bosatt i Norge ved seks års alder. Av disse var 1814 registrert én eller flere ganger med Tourettes syndrom som hoved- eller bidiagnose i alderen 6-14 år. Gjennomsnittlig fikk barna første diagnose det året de fylte ni år. I året de fylte 12 år var andelen $0,43 \%$, fordelt på $0,71 \%$ hos gutter og $0,15 \%$ hos jenter (figur 1). De fleste fylkene lå nær landsgjennomsnittet (figur 2), med unntak av Oslo som lå under, med o,15\%, og Hedmark, Sør-Trøndelag og Aust-Agder som lå over, med henholdsvis o,63\%, o,71\% og 1,23\%. Andelene med diagnoser har vært stabile hos begge kjønn og i alle aldersgrupper i årene 2008-16 (figur 3). Både hos gutter og jenter var andelene høyest i aldersgruppen 10-13 år. 


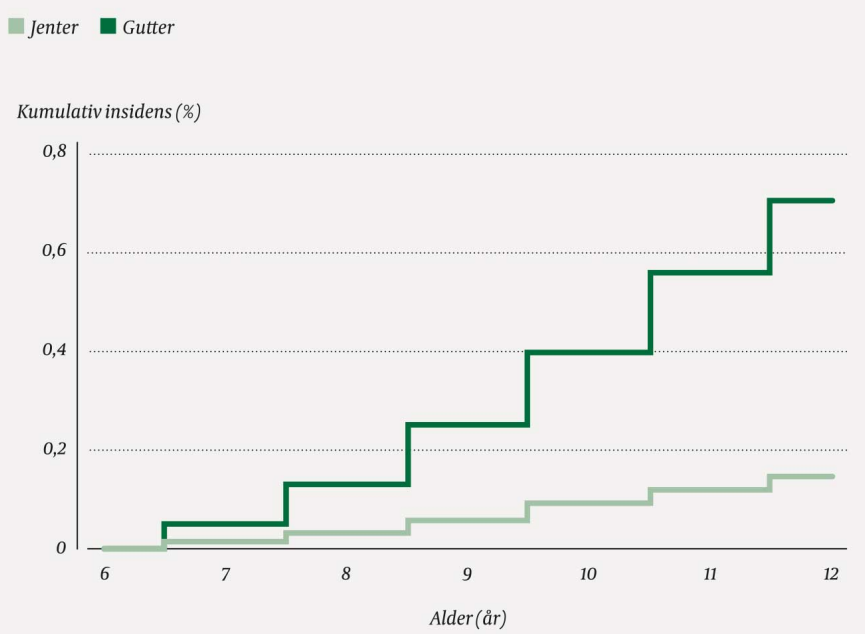

Figur 1 Prosentandeler med diagnostisert Tourettes syndrom $i$ alderen 6-12 år, fordelt på alder og kjønn. Data fra Norsk pasientregister og Folkeregisteret 2008-16.

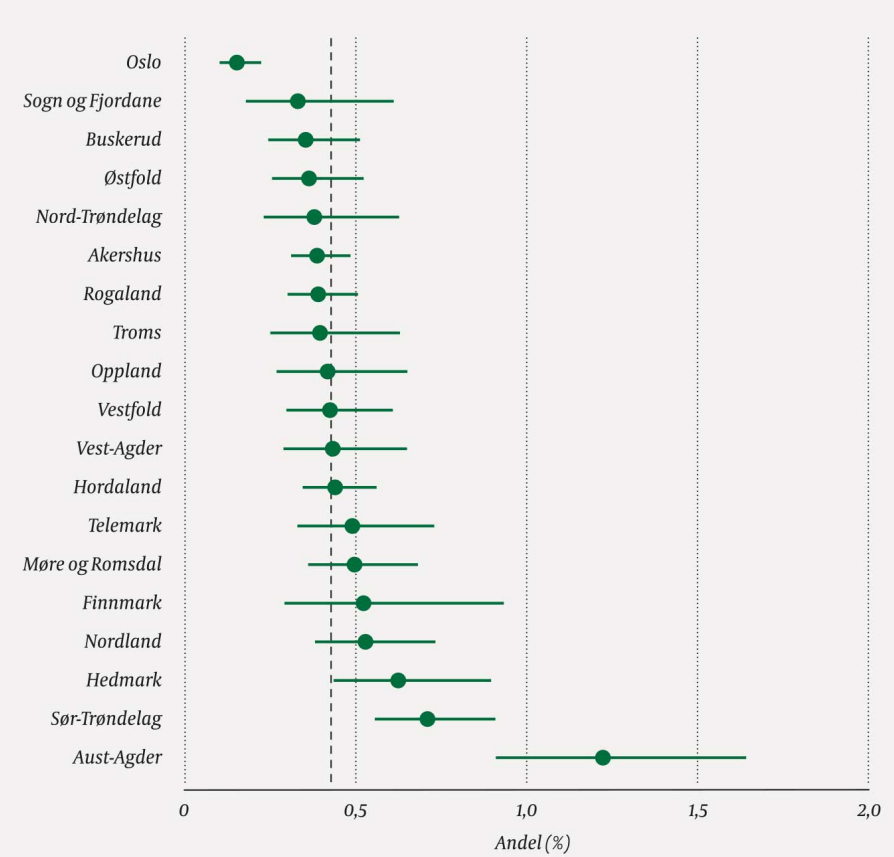

Figur 2 Prosentandeler med Tourettes syndrom ved 12 års alder, fordelt på fylke. Vertikal stiplet linje er landsgjennomsnitt. Horisontale linjer er 99,7 \% konfidensintervaller. Data fra Norsk pasientregister og Folkeregisteret 2008-16.
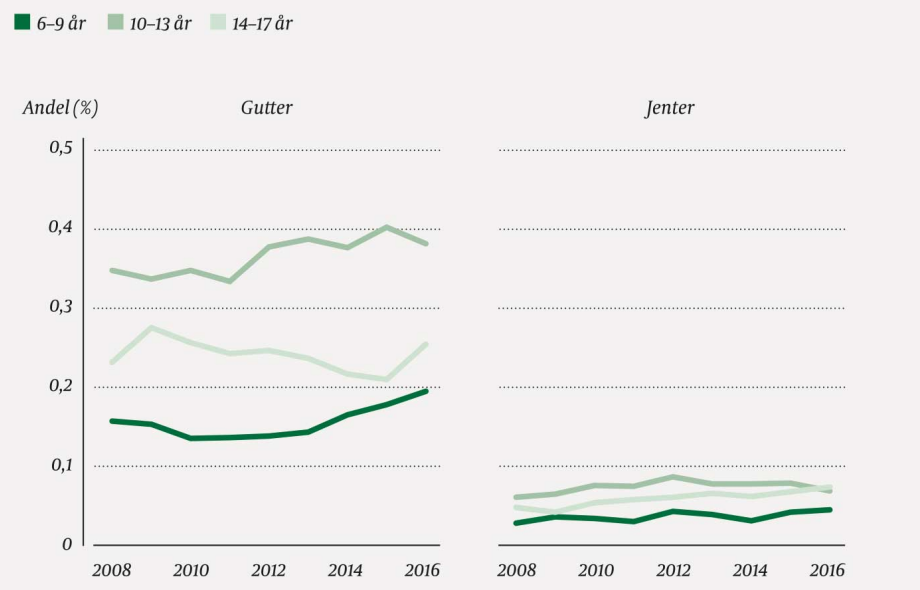

Figur $3_{3}$ Prosentandeler registrert med Tourettes syndrom i hvert kalenderår. Data fra Norsk 
pasientregister og Folkeregisteret 2008-16.

Av de 1814 barna og ungdommene med Tourettes syndrom var 1277 (70\%) også registrert med andre psykiatriske og nevrologiske diagnoser (tabell 1). Den vanligste komorbide diagnosen var ADHD, som var registrert hos $50 \%$. Autismespekterforstyrrelser var registrert hos $11 \%$. Det var også mange som hadde spesifikke utviklingsforstyrrelser, det vil si språkforstyrrelser ( $9 \%)$, lærevansker (6\%), blandede utviklingsforstyrrelser (4\%) og koordinasjonsforstyrrelser (2\%). Psykisk utviklingshemning var registrert hos $3 \%$. Vanlige psykiatriske diagnoser var tvangslidelse (7\%), angstlidelser (7\%), tilpasningsforstyrrelser (7\%), atferdsforstyrrelser (6\%) og ikke-organisk enurese (7\%). Av nevrologiske diagnoser var epilepsi (6\%) og søvnforstyrrelser (4\%) vanligst.

\section{Tabell 1}

Psykiatriske og nevrologiske tilleggsdiagnoser blant barn og ungdom som var registrert med Tourettes syndrom i alderen 6-17 år $(\mathrm{N}=1814)$. Gjelder diagnosegrupper registrert hos mer enn $1 \%$ av barn og ungdom med Tourettes syndrom.

\begin{tabular}{|llr|}
\hline Diagnosegruppe & ICD-10-koder & $\begin{array}{r}\text { Antall } \\
\text { (\%) }\end{array}$ \\
\hline Depressiv episode/depresjon & F32, F33, F92.0 & $23(1)$ \\
\hline Angstlidelser & $\mathrm{F} 40$, F41, F92.8, F93.0, F93.1, F93.2 & $129(7)$ \\
\hline Tvangslidelse & $\mathrm{F} 42$ & $128(7)$ \\
\hline Tilpasningsforstyrrelse & $\mathrm{F} 43$ & $66(4)$ \\
\hline Ikke-organiske søvnforstyrrelse & $\mathrm{F} 51$ & $23(1)$ \\
\hline Psykisk utviklingshemning & $\mathrm{F} 70-\mathrm{F} 79$ & $48(3)$ \\
\hline Språkforstyrrelse & $\mathrm{F} 80$ & $158(9)$ \\
\hline Lærevansker & $\mathrm{F} 81$ & $117(6)$ \\
\hline Koordinasjonsforstyrrelse & $\mathrm{F} 82$ & $34(2)$ \\
\hline Blandede utviklingsforstyrrelser & $\mathrm{F} 83$ & $66(4)$ \\
\hline Autismespekterforstyrrelse & $\mathrm{F} 84$ & $200(11)$ \\
\hline Hyperkinetisk forstyrrelse (ADHD) & $\mathrm{F} 90$ & $909(50)$ \\
\hline Atferdsforstyrrelse & $\mathrm{F} 91$ & $102(6)$ \\
\hline Ikke-organisk enurese & $\mathrm{F} 98.0$ & $131(7)$ \\
\hline Ikke-organisk enkoprese & $\mathrm{F98.1}$ & $27(1)$ \\
\hline Andre spesifiserte atferdsforstyrrelser & $\mathrm{F} 98.8$ & $31(2)$ \\
\hline Epilepsi & $\mathrm{G} 40$ & $106(6)$ \\
\hline Migrene & $\mathrm{G} 43$ & $28(2)$ \\
\hline Søvnforstyrrelse & $\mathrm{G} 47$ & $65(4)$ \\
\hline
\end{tabular}

I populasjonen var det 878 (o,16\%) som var registrert med diagnosekode F95.1 (Kroniske motoriske eller vokale «tics»). Av disse var 140 (16\%) også registrert med diagnosekode for Tourettes syndrom (F95.2).

Det var 754 barn og ungdommer i alderen 6-17 år som fikk diagnosen Tourettes syndrom for første gang i årene 2013 og 2014. Mange av disse brukte psykofarmaka eller andre medikamenter med virkning på sentralnervesystemet (tabell 2). De to vanligste medikamentkategoriene var ADHD-medikamenter (37\%) og sovemedisiner (23\% til sammen). Bruk av antipsykotika var registrert hos $16 \%$. Av de 122 som hadde fått antipsykotika, hadde 105 ( $86 \%$ ) fått risperidon. For risperidon var refusjonskoden oftest atferdsproblemer. Det var ikke registrert psykoselidelser hos noen av barna. Klonidin (til samtidig behandling av Tourettes syndrom og ADHD) var brukt hos $1 \%$. 
Forskrivning av psykofarmaka, antiepileptika og hypnotika første år etter diagnostisering av Tourettes syndrom hos barn og ungdom $(\mathrm{N}=754)$.

\begin{tabular}{|lr|}
\hline Medikamentgruppe (ATC-kode) & Antall (\%) \\
\hline Antipsykotika (NO5A) & $120(16)$ \\
\hline Klonidin (NO2CX02) & $11(1)$ \\
\hline Antidepressiver (NO6A) & $38(5)$ \\
\hline Angstdempende medikamenter (NO5B) & $6(1)$ \\
\hline Stimulantia (ADHD-medikamenter) (NO6B) & $279(37)$ \\
\hline Antiepileptika (NO3A) & $24(3)$ \\
\hline Melatonin (NO5CH01) & $154(20)$ \\
\hline Alimemazin (R06AD01) & $24(3)$ \\
\hline
\end{tabular}

\section{Diskusjon}

Blant norske barn født i årene 2002-10 estimerte vi at 0,43\% vil ha fått diagnosen Tourettes syndrom ved 12 års alder. Andelen er lavere enn gjennomsnittsprevalensen på o,77\% som er funnet i studier av aldersgruppen 6-15 år i andre land (2). Forskjellen kan tyde på at en del barn som tilfredsstiller diagnosekriteriene for Tourettes syndrom, ikke får diagnosen $\mathrm{i}$ Norge. Gjennomsnittsalderen på diagnosetidspunktet ( 9 år) er også noe høy sett i forhold til at symptomene oftest debuterer ved 5-6 års alder.

En del barn med diagnosekode for Tourettes syndrom (F95.2) er også registrert med diagnosekode for kroniske motoriske eller vokale tics (diagnosekode F95.1). Hvis kode F95.1 brukes på barn som egentlig tilfredsstiller kriteriene for Tourettes syndrom, vil det være en del av årsaken til at andelen med diagnosen er lavere enn i befolkningsstudier. Registrering av begge koder hos samme barn kan også ha en naturlig forklaring ved at et barn debuterer med én type tics (motoriske eller vokale) først og deretter går over til ha både motoriske eller vokale tics. Våre data tillater ikke sikre konklusjoner om dette.

I Oslo er andelen med Tourettes syndrom påfallende lav, mens den er høy i Aust-Agder. Hedmark og Sør-Trøndelag ligger over landsgjennomsnittet og er mest på linje med det internasjonale prevalensestimatet (2). Vi vet ikke hvorfor andelene varierer mellom fylkene. Sannsynligvis skyldes det ulik henvisnings- og diagnosepraksis, eller ulik gjenkjenningskompetanse. Vi kjenner ikke til epidemiologiske studier som har vist at den reelle risikoen for Tourettes syndrom varierer geografisk.

Flertallet av barn og ungdom med Tourettes syndrom har én eller flere andre psykiatriske eller nevrologiske diagnoser, og søvnproblemer er utbredt. Det er kjent fra før at ADHD, lærevansker, atferdsforstyrrelser og emosjonelle lidelser er vanlige hos barn og ungdom med Tourettes syndrom $(1,4)$. Mer uventet var den høye andelen med autismespekterforstyrrelser (11\%). Dette er ikke rapportert tidligere. Andelen med tvangslidelse ( $7 \%$ ) var overraskende lav, ettersom andre studier har vist at $40-60 \%$ av personer med Tourettes syndrom har dette (4). Forekomsten av tvangslidelse kan være lavere i vår populasjon, men det kan også hende at mange har symptomer forenlige med en tvangslidelse uten at det er satt en diagnose for det. Tvangstanker og tvangshandlinger kan være omfattende og plagsomme. Det er viktig å utrede og diagnostisere eventuell tvangslidelse, fordi det er forutsetningen for at barna får tilgang til kognitiv terapi eller annen behandling.

Det var $16 \%$ som hadde fått forskrevet antipsykotika i året etter at diagnosen var stilt, og de fleste hadde fått risperidon. Refusjonskoden var som regel atferdsproblemer, men sannsynligvis var risperidon oftest gitt for å behandle tics eller samtidige tics og atferdsproblemer. Dette er i tråd med anbefalingene i norske og europeiske retningslinjer $(6,7)$. At vi avgrenset studien til medikamenter forskrevet de første 365 dagene etter at 
diagnosen ble stilt, gjør at vi ikke har fanget opp behandling som er startet senere i forløpet. Dermed kan andelen som på ett eller annet tidspunkt prøver medikamenter, være høyere enn $16 \%$.

Det er utilfredsstillende at Tourettes syndrom ikke er godkjent som indikasjon eller refusjonsgrunnlag for risperidon, som anbefales mot tics i internasjonale faglige retningslinjer. Det er også ulogisk at barn kan få individuell refusjon for aripiprazol, mens voksne ikke kan få det.

For de andre medikamentene som ble brukt hos barn og ungdom med Tourettes syndrom, samsvarte bruken med de øvrige psykiatriske og nevrologiske diagnosene som var registrert. Unntaket var at andelene som brukte sovemedisiner, var mye høyere enn andelene som hadde diagnoser for søvnforstyrrelser.

Studien vår baserer seg på helseregisterdata. Vi har ikke gått gjennom journaler og kvalitetssikret diagnosedata. Vi har data for utleverte medikamenter, men vi vet ikke med sikkerhet at medikamentene er brukt, og vi har ikke data for ikke-medikamentell behandling.

\section{Konklusjon}

Andelene barn som får diagnostisert Tourettes syndrom i Norge ligger under gjennomsnittsprevalensen i befolkningsstudier. Diagnosebruken varierer betydelig mellom fylkene. Det er behov for mer kunnskap om forekomst av Tourettes syndrom, kvalitet på utredninger og diagnostikk, effekter av medikamentell og ikke-medikamentell behandling samt langsiktig prognose. Med langsiktig prognose tenker vi ikke bare på forløpet av selve tilstanden, men også på tilleggslidelsene og hvordan barna klarer seg i skole og arbeidsliv. Ved å kombinere data fra helseregistre, helseundersøkelser og journalgjennomganger har vi i Norge forutsetninger for å utføre befolkningsbaserte studier av Tourettes syndrom og dermed bidra til å avhjelpe mangelen på kunnskap.

\section{HOVEDFUNN}

Blant norske barn født i årene 2002-10 estimerte vi at 0,43 \% får diagnostisert Tourettes syndrom innen 12 års alder.

Andelene varierte betydelig mellom fylkene.

Flertallet hadde andre psykiatriske eller nevrologiske diagnoser i tillegg.

16 \% fikk antipsykotika i året etter at diagnosen var stilt, sannsynligvis til behandling av tics.

\section{LITTERATUR:}

1. Grøholt B, Garløv I, Weidle B et al. Lærebok i barnepsykiatri. 5. utgave. Oslo: Universitetsforlaget, 2015 .

2. Knight T, Steeves T, Day L et al. Prevalence of tic disorders: a systematic review and meta-analysis. Pediatr Neurol 2012; 47: 77-90. [PubMed][CrossRef]

3. Atladottir HO, Gyllenberg D, Langridge A et al. The increasing prevalence of reported diagnoses of childhood psychiatric disorders: a descriptive multinational comparison. Eur Child Adolesc Psychiatry 2015; 24: 173-83. [PubMed][CrossRef]

4. Robertson MM, Eapen V, Singer HS et al. Gilles de la Tourette syndrome. Nat Rev Dis Primers 2017; 3 : 16097. [PubMed][CrossRef]

5. Verdellen C, van de Griendt J, Hartmann A et al. European clinical guidelines for Tourette syndrome and other tic disorders. Part III: behavioural and psychosocial interventions. Eur Child Adolesc Psychiatry 2011; 20: 197-207. [PubMed][CrossRef] 
6. Regional retningslinje for utredning og behandling av Tourettes syndrom. Oslo: Helse Sør-Øst, 2013. https://oslo-universitetssykehus.no/seksjon/regional-kompetansetjeneste-for-autisme-adhd-tourettessyndrom-og-narkolepsi-helse-sor-ost/Documents/RR-TSOslo\%2oUniversitetssykehus.pdf Lest 8.8.2019.

7. Roessner V, Plessen KJ, Rothenberger A et al. European clinical guidelines for Tourette syndrome and other tic disorders. Part II: pharmacological treatment. Eur Child Adolesc Psychiatry 2011; 20: 173-96. [PubMed][CrossRef]

Publisert: 12. november 2019. Tidsskr Nor Legeforen. DOI: 10.4045/tidsskr.19.0411

Mottatt 10.1.2019, første revisjon innsendt 26.8.2019, godkjent 14.10.2019.

(C) Tidsskrift for Den norske legeforening 2020. Lastet ned fra tidsskriftet.no 